\title{
Arrival Direction of VLF Emissions and Corresponding Activities in Aurora and Geomagnetic Pulsations
}

\author{
K. HAYAShi, ${ }^{*, * * * * *}$ K. Tsuruda, ${ }^{* *}$ S. KoKUbUn, ${ }^{* * *}$ \\ T. OGuti, ${ }^{* *}$ R.E. Horita, ${ }^{* * * *}$ and T. WAtAnABE* \\ *Department of Geophysics and Astronomy, University of British Columbia, Canada \\ **Institute of Space and Aeronautical Science, University of Tokyo, Tokyo, Japan \\ ***Geophysics Research Laboratory, University of Tokyo, Tokyo, Japan \\ ****Department of Physics, University of Victoria, Canada
}

(Received February 7, 1978)

Herein are reported some features of VLF emissions during magnetic substorms based on the data obtained with the Manitoba station net in September 1976. VLF direction finding for elliptically polarized electromagnetic waves (E-DF) (TsuRUDA and HAyashi, 1975) was carried out at Churchill and at Thompson together with highly sensitive TV systems for auroral observation and induction magnetometers. Induction magnetometers were also operated at the three other locations (Gillam, Island Lake, Star Lake).

On 22 September 1976, small magnetic substorms were observed between $3 \mathrm{hr}$ and $7 \mathrm{hr}$ UT at local midnight (Fig. 1). From 0310 to $0313 \mathrm{UT}$, the arrival direction of auroral hiss was observed to change from the north to the south at both stations. Unfortunately the sky was mostly covered by clouds at this time. Though the tendency of changes is similar at each station, the mapped location of the exit points of waves from the ionosphere, assuming an altitude of $110 \mathrm{~km}$, are about $300 \mathrm{~km}$ apart. Auroral hiss observed at each station seems to be generated in the regions neighboring to the stations, although the disturbance was activated over a wider area at this moment. At 0520 UT the sky was clear at Thompson. An auroral

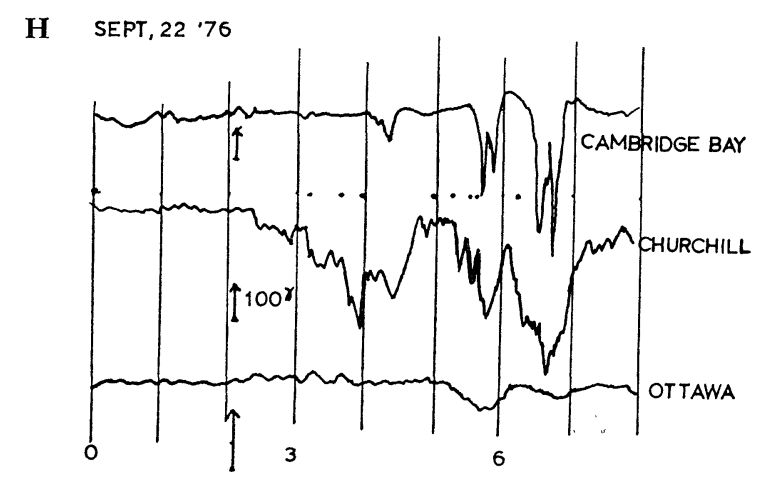

Fig. 1

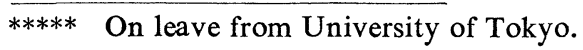


expansion is seen to start in the direction of Churchill and its low-latitude boundary is propagating to the south-west. At $0521 \mathrm{UT}$ an active auroral arc, accompanying successive bright and rapid motions reaches $30^{\circ}$ from the zenith in the Thompson's meridian plane. The other arc is brightened and stretched toward the east at the northern boundary of the auroral activity. At 0522 UT the active low-latitude arc is in the south of Thompson, but the northern activity is decreased.

Direction finding analysis for the interval between 0520 and 0522 indicates that auroral hiss comes from the north around 0521 at both stations, and from the south at the end of this interval at Thompson. In Fig. 2 is shown the locations of auroras and arrival direction of auroral hiss mapped at the height of $110 \mathrm{~km}$. This example also suggests that arrival direction of auroral hiss is closely related to local auroral activities. From 0630 to 0650 , and from 0720-0750 UT, in the recovery phase of the substorms, chorus (HAYASHI and KOKUBUN, 1971) becomes active overhead or to the south of Thompson where dim pulsating aurora is flashing like live charcoals, and geomagnetic pulsations with a period of about $10 \mathrm{sec}$ (Pi-C type) are also observed predominantly in the $D$-component.

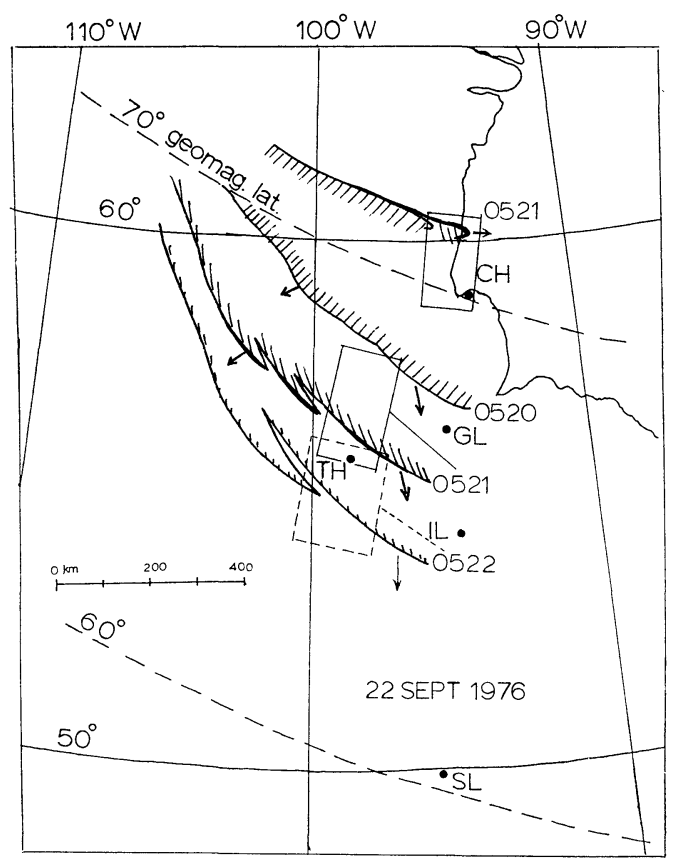

Fig. 2

\section{REFERENCES}

Hayashi, K. and S. Kokubun, VLF emissions during post breakup phase of substorm, Rep. Ionos. Space Res. Japan, 25, 369-382, 1971.

Tsuruda, K. and K. HAYAshi, Direction finding technique for elliptically polarized VLF electromagnetic waves and its application to the low latitude whistlers, J. Atmos. Terr. Phys., 37, 11931202, 1975. 